\title{
Effects of induced hypothermia on somatosensory evoked potentials in patients with chronic spinal cord injury
}

\author{
K C Hayes, J T C Hsieh, P J Potter, D L Wolfe, G A Delaney, A R Blight \\ Department of Physical Medicine \& Rehabilitation, Parkwood Hospital and The \\ University of Western Ontario, London, Ontario, Canada.
}

\begin{abstract}
We have investigated the effects of mild whole body hypothermia on the amplitude and latency of somatosensory evoked potentials (SEPs) in control subjects $(n=12)$ and patients $(n=15)$ with chronic compressive or contusive spinal cord injury (SCI). Mild hypothermia $\left(-1{ }^{\circ} \mathrm{C}\right)$ was induced by controlled circulation of propylene glycol through a 'microclimate' head and vest garment while reductions in oral and limb temperatures were monitored. Cooling induced a delayed onset and reduced amplitude of tibial nerve SEPs in control subjects. All SCI patients with recordable SEPs $(n=11)$ showed similarly delayed onset of the cortical response. In contrast to the controls, nine of the 11 SCI patients showed an increase in amplitude of cortical SEPs. In three of these patients the increase in amplitude exceeded $100 \%$ of the precooling values. The coolinginduced changes in SEP amplitude and latency reversed on rewarming for both groups. The cooling-induced increases in cortical SEP amplitude support the a priori hypothesis that cooling would enhance central conduction in some SCI patients with conduction deficits due to focal demyelination.
\end{abstract}

Keywords: SEPs; spinal cord injury; demyelination; hypothermia.

\section{Introduction}

Following a compressive or contusive spinal cord injury (SCI) some axons are physically disrupted, either by the initial insult or in the subsequent cascade of biochemical and immunological events that follow, ${ }^{1-4}$ some axons may be left undamaged, ${ }^{5}$ and other axons are left physically intact but demyelinated. ${ }^{6-13}$ Although well recognized in animal models of spinal cord injury, it is only recently that compression-induced focal demyelination has been clearly demonstrated in pathological analyses of human cord tissue. ${ }^{14}$ Bunge et al, ${ }^{14}$ for example, observed 'dramatic focal demyelination of the dorsal columns (without concomitant major axon loss)' in specimens taken from the cervical cord of a 78 year old patient who had experienced cord compression for approximately 12 years.

Demyelination exposes internodal voltage-gated 'fast' potassium $\left(\mathrm{K}^{+}\right)$channels ${ }^{15.16}$

Correspondence: KC Hayes PhD, Director of Research, Parkwood Hospital, 801 Commissioners Road East, London, Ontario, Canada N6C 5J 1 . and alters the input impedance of the internode causing the action potential to conduct decrementally with (a) conduction failure or (b) marked slowing of conduction velocity or (c) inability to sustain repetitive impulse discharges. ${ }^{17-22}$ These conduction deficits most likely contribute to the paresis and loss of sensation experienced by SCI patients.

Conduction deficits due to demyelination have been shown to be temperature sensitive. ${ }^{23.24}$ Reducing temperature increases the rate constant of $\mathrm{Na}^{+}$channel inactivation and therefore prolongs the action current and increases the safety factor for conduction. ${ }^{7.23-31)}$ Thus, systematic elevations in temperature induce conduction failure in progressively more demyelinated neurons ${ }^{29}$ and reductions in temperature restore conduction. The therapeutic benefits of cooling in demyelinating disease such as multiple sclerosis (MS) are well known. ${ }^{31-34}$ Similarly, in spinal cord injured cats, Blight ${ }^{23}$ has shown that a $\mathrm{K}^{+}$channel blocking agent, 4-Aminopyridine (4-AP), affected the temperature at which conduction block 
occurred. Of 17 axons in which it was possible to demonstrate conduction failure, apply 4-AP and test conduction again, three showed substantial improvement in the safety factor for conduction within a few minutes, with the blocking temperature raised from $28^{\circ}, 29^{\circ}$ and $30^{\circ} \mathrm{C}$ to $>37^{\circ} \mathrm{C}$.

The present study tested the hypothesis that whole body hypothermia would attenuate the central sensory conduction deficits in some SCI patients with compressive or contusion injuries. Implicit was the assumption that induced whole body hypothermia of $-1{ }^{\circ} \mathrm{C}$ (oral temperature) would cause a sufficient, but indeterminate, degree of cooling in the spinal cord to ameliorate the conduction deficits. Oral temperature changes as small as $0.2-0.5^{\circ} \mathrm{C}$ have previously been shown to markedly alter demyelination induced signs and symptoms in patients with multiple sclerosis. ${ }^{35.36}$ It was reasoned that demonstration of coolinginduced enhancement of central conduction in certain patients would help identify individuals with conduction failure due to demyelination who might benefit from a $\mathrm{K}^{+}$ channel blocking agent such as $4-\mathrm{AP} .{ }^{37}$

\section{Methods}

\section{Subjects}

Twelve healthy adult volunteers provided informed consent to participate as control subjects. Seven of the subjects were female. The mean age of the group was $26.6 \pm 4.6$ years.

Fifteen volunteer patients with spinal cord injury (mean age $32 \pm 11.5$ years) served as the principal study group. Their clinical characteristics are reported in Table I. Eleven of the patients sustained injuries as a consequence of motor vehicle or sports related accidents; one had an anterior spinal artery syndrome as a result of an aortic tear, one had cord compression from multiple myeloma, one developed a central cord syndrome as a result of vascular insufficiency secondary to a fall, and one developed an anterior cord syndrome secondary to a sports injury. Prior to the study one patient was taking Valium as a spasmolytic, six patients were taking Lioresal, and one patient was taking an antibiotic for urinary tract infection. All medications were discontinued for the 6 hour duration of the study.

\section{Protocol}

The control subjects and patients all underwent electrodiagnostic assessment of SEPs and central conduction prior to the cooling procedure, at maximal cooling, and after being rewarmed to their baseline body temperature.

Total body hypothermia was induced by controlled circulation of a coolant (propylene glycol) through a microclimate headvest garment (Life Support Systems Inc Mark VII) worn over light underclothing. A fan directed on the subject assisted heat loss through convection. The cooling was normally continued until oral temperature had reduced by $1{ }^{\circ} \mathrm{C}$. The duration of cooling normally varied between 1 and 2 hours. After maximum cooling, the microclimate garment was removed and replaced with a heating blanket, the fan turned off, and the subjects rewarmed to their baseline temperature.

Oral temperature was sampled every 15-20 minutes using a Questemp II data logging thermometer (Quest Electronics). Auricular temperature was monitored con-

Table I Physical and clinical characteristics of control subjects and SCI patients

\begin{tabular}{|c|c|c|c|c|c|c|c|c|c|c|c|c|c|}
\hline \multirow{3}{*}{ Subjects } & \multicolumn{6}{|c|}{ Physical characteristics } & \multicolumn{7}{|c|}{ Clinical characteristics } \\
\hline & \multicolumn{2}{|c|}{ Sex } & \multicolumn{2}{|c|}{ Age } & \multicolumn{2}{|c|}{$\begin{array}{c}\text { Level } \\
\text { of injury }\end{array}$} & \multicolumn{5}{|c|}{ Frankel classification } & \multicolumn{2}{|c|}{$\begin{array}{c}\text { Months } \\
\text { since injury }\end{array}$} \\
\hline & $\mathrm{M}$ & $\mathrm{F}$ & $\begin{array}{c}\text { Mean } \\
266\end{array}$ & $\mathrm{SD}$ & Para & Quad & A & B & $\mathrm{C}$ & $\mathrm{D}$ & E & Mean & SD \\
\hline $\begin{array}{l}\text { Contr } \\
\text { SCI }\end{array}$ & 12 & 3 & $\begin{array}{l}26.6 \\
32.3\end{array}$ & $\begin{array}{r}4.6 \\
11.5\end{array}$ & 3 & 12 & 2 & 1 & 8 & 4 & 0 & 63.1 & 67.7 \\
\hline
\end{tabular}


tinuously as an additional index of central temperature $^{38}$ using either the Questemp II or a Thermoscan infrared ear thermometer, and peripheral limb skin temperature was recorded from a Model 49TA digital thermometer (Yellow Springs Inst Co) with thermocouple located over the dorsum of the foot (for two SCI patients, in whom only median nerve SEPs could be recorded, the thermocouple was located over the dorsum of the hand) with recordings taken every 15 minutes.

Somatosensory evoked potentials were elicited by $3.1 \mathrm{~Hz}$ stimulation $(500 \mu \mathrm{s})$ delivered bilaterally to the tibial nerve at the level of the medial malleolus from a Devices stimulator (Model 3072) and electrode. In two quadriplegic SCI patients, median nerve stimulation at the wrist was employed (using the same stimulus parameters), when SEPs were absent following tibial nerve stimulation. SEP recordings were obtained from scalp electrodes at $\mathrm{C}_{\mathrm{z}}-\mathrm{F}_{\mathrm{z}}$ (tibial nerve) or $\mathrm{C}_{3}-\mathrm{F}_{\mathrm{z}}$ (median nerve). Signals were amplified ( $3 \mathrm{db}$ down at $10 \mathrm{~Hz}-2 \mathrm{kHz})$ in a DISA Type 15C01 amplifier, A-D converted and stored (PCM-4/8 Medical Systems Inc) prior to signal averaging and display. At least two averages $(\geqslant 2000$ stimulations each) were obtained prior to cooling, after cooling and after rewarming. The latency and amplitude values of the cortical SEP components were based on the average of the two series. Computer-aided digitization ( $0.5 \mathrm{~ms}$ resolution) assisted determination of latencies, and visual interpolation was employed when there was incomplete fusion of peaks. ${ }^{39}$

During tibial nerve stimulation, compound nerve action potentials were recorded from bipolar surface electrode recordings over the popliteal fossa (PF). Spinal potentials were also obtained from bipolar surface electrodes positioned on the skin overlying the first lumbar vertebra (L1). With median nerve stimulation, bipolar recordings of sensory potentials were obtained from surface electrodes positioned over the antecubital fossa and Erb's point. The latency recordings from these potentials enabled dissociation of peripheral nerve conduction velocity changes from any changes in central conduction.

\section{Results}

All control subjects tolerated the cooling without discomfort. At an oral temperature reduction of $1.0^{\circ} \mathrm{C}$ intermittent shivering was usually evident in the face, upper limbs and trunk. With the exception of two patients who reported generalized discomfort (and discontinued cooling), the SCI patients tolerated the cooling for approximately 90 minutes without concern. Each provided subjective spontaneous reports of cooling and exhibited facial pallor. In each subject the upper and lower limbs were pale and cool to touch. Subjects warmed to their baseline temperature within 2 hours of the end of cooling.

\section{Hypothermia}

The extent and rate of cooling in the lower limbs for the control subjects and SCI patients are reported in Table II. The lower limb temperature of the control subjects reduced $(p<0.05)$ by an average of $-2.52 \pm 0.84{ }^{\circ} \mathrm{C}$ over a period of $\approx 1.25$ hours. The extent of cooling $(-3.65$ $\left.\pm 1.5^{\circ} \mathrm{C}\right)$ was greater $(p<0.05)$ for the SCI patients. The average rate of cooling for the controls was $\bar{x}=-1.91 \pm 0.14{ }^{\circ} \mathrm{C} /$ hour and for SCI patients it was significantly $(p<0.05)$ faster $\bar{x}=-2.36 \pm 0.19^{\circ} \mathrm{C}$ /hour. In the two quadriplegic patients in whom median nerve SEPs were recorded, the extent of upper limb cooling was $\bar{x}=$ $-2.4{ }^{\circ} \mathrm{C}$ and the rate was $\bar{x}=-2.3^{\circ} \mathrm{C}$ /hour.

A differential rate of cooling between control subjects and SCI patients was also evident in the auricular temperature (Table II). The auricular temperatures cooled at a rate of $-0.64 \pm 0.07^{\circ} \mathrm{C}$ /hour for control subjects and $-0.86 \pm 0.05^{\circ} \mathrm{C} /$ hour for SCI patients $(p<0.05)$. The oral temperature of control subjects reduced at a rate of $-0.78 \pm 0.04{ }^{\circ} \mathrm{C} /$ hour whereas the SCI patients cooled at a rate of $-0.63 \pm$ $0.03{ }^{\circ} \mathrm{C}$ /hour. The rate of cooling of oral temperature in the SCI patients yielded Pearson product moment correlations with the level of lesion $(r=0.43 ; p>0.05)$, with the impairment $(r=0.33 ; p>0.05)$, and with physical stature $(r=0.54 ; p<0.05)$. The multiple linear regression of these three variables with the rate of cooling yielded 
Table II Induced hypothermia in control subjects and SCI patients

\begin{tabular}{|c|c|c|c|c|c|c|c|c|c|}
\hline & \multicolumn{2}{|c|}{ Peripheral } & \multirow[b]{2}{*}{$\mathrm{R}^{2}$} & \multicolumn{2}{|c|}{ Auricular } & \multirow[b]{2}{*}{$\mathrm{R}^{2}$} & \multicolumn{2}{|r|}{ Oral } & \multirow[b]{2}{*}{$\mathrm{R}^{2}$} \\
\hline & $\begin{array}{c}\text { Extent } \\
\text { (deg C) }\end{array}$ & $\begin{array}{c}\text { Rate } \\
(\mathrm{deg} / \mathrm{hr})\end{array}$ & & $\begin{array}{c}\text { Extent } \\
\text { (deg C) }\end{array}$ & $\begin{array}{c}\text { Rate } \\
\text { (deg/hr) }\end{array}$ & & $\begin{array}{c}\text { Extent } \\
\text { (deg C) }\end{array}$ & $\begin{array}{c}\text { Rate } \\
(\mathrm{deg} / \mathrm{hr})\end{array}$ & \\
\hline Control & $-2.52[0.84]$ & $-1.91(0.14)$ & 0.97 & $-0.98[1.01]$ & $-0.64(0.07)$ & 0.93 & $-1.02[0.40]$ & $-0.78(0.04)$ & 0.98 \\
\hline Patients & $-3.65[1.45]$ & $-2.36(0.19)$ & 0.96 & $-1.34[0.62]$ & $-0.86(0.05)$ & 0.98 & $-0.98[0.51]$ & $-0.63(0.03)$ & 0.99 \\
\hline
\end{tabular}

[ ] refers to the standard deviation of the extent.

( ) refers to the standard error of the linear regression beta coefficient from which the rate constant was determined.

$\mathrm{R}^{2}$ refers to the goodness of fit of linear regression analysis.

These data include the results from two SCI patients who discontinued cooling prematurely (ie failed to reach target of $-1{ }^{\circ} \mathrm{C}$ oral) because of discomfort. They discontinued after oral temperature reductions of $0.1^{\circ} \mathrm{C}$ and $0.4^{\circ} \mathrm{C}$ respectively. The peripheral cooling data are based on $n=13$ patients (lower limb only) whereas the auricular and oral data are based on $n=15$.

$\mathrm{R}=0.86 \quad(p<0.05)$. Oral and auricular temperatures continued to drop an additional 0.1 or $0.2^{\circ} \mathrm{C}$ in the $10-15$ minutes immediately after the cooling garment was discontinued. This 'after-fall' phenomenon was evident in 11 of the 14 control subjects and 13 of the $15 \mathrm{SCI}$ patients and is attributable to the core-surface temperature gradient established by surface cooling. ${ }^{+1}$

\section{Peripheral conduction}

Cooling induced reductions in peripheral nerve conduction velocities (NCV) in both the control subjects $(t=4.18 ; d f=10$, $p<0.05)$ and SCI patients $(t=3.52$; $d f=8, p<0.05)$ (Table III). These reductions in NCV were generally greater in the distal segment of the tibial nerve (medial malleolus-popliteal fossa) than in the proximal segment (popliteal fossa-L1). Similarly they were greater in the distal segment of the median nerve (wrist to antecubital fossa) than in the proximal segment (antecubital fossa to C5). The latencies of sensory potentials recorded at $\mathrm{PF}$ and $\mathrm{Ll}$ are also reported in Table III.

\section{Somatosensory evoked potentials \\ Control subjects}

Table III reports the latency and amplitude values for various components of the SEPs under the precooling, cooled and rewarmed conditions for both control and SCI groups.
Cooling induced a delay in onset of the $\mathrm{N}_{33}$ component of the tibial nerve SEP from a precooling value of $\bar{x}=33.44 \pm 1.50 \mathrm{~ms}$ to a post cooling value $\bar{x}=35.91 \pm 2.50 \mathrm{~ms}$ in control subjects $(t=3.65 ; \quad d f=11, \quad p<$ $0.05)$. Nine of the twelve subjects revealed prolonged latencies of $\mathrm{N}_{33}$. The earliest positive component $\left(\mathrm{P}_{38}\right)$, which oftentimes provided a more definitive and reliable peak in the SEP waveform, was similarly delayed from a precooling value of $\bar{x}=39.16 \pm 0.16$ to a postcooling value of $\bar{x}=41.2 \pm 2.69$. The delay in onset of the early cortical component(s) was principally attributable to changes in the peripheral nerve conduction time from stimulation to L1 since central conduction time $\left(\mathrm{L} 1-\mathrm{N}_{33}\right)$ did not change from the precooling value $\bar{x}=10.93$ $\pm 1.21 \mathrm{~ms}$ to the value after cooling $\bar{x}=10.93 \pm 2.96 \mathrm{~ms}$. The amplitude of $\mathrm{N}_{33}$ showed a small but significant decrease from a precooling group mean value of $\bar{x}=1.89 \pm 0.99 \mu \mathrm{V}$ to a value of $1.70 \pm$ $1.01 \mu \mathrm{V}(t=2.5, d f=11, p<0.05)$. Ten of the twelve control subjects showed reductions in $\mathrm{N}_{33}$ amplitude. The changes in latency and the changes in amplitude of SEP cortical components all reversed on warming.

Figure 1 shows an illustrative set of SEP records from a control subject in which the latency of $P_{38}$ was increased from $40.6 \mathrm{~ms}$ to $43.3 \mathrm{~ms}$ with cooling and the amplitude of the $\mathrm{N}_{33}-\mathrm{P}_{38}$ component was reduced from $1.11 \mu \mathrm{V}$ peak-to-peak to $0.67 \mu \mathrm{V}$. The 
Table III Effects of cooling on peripheral and central conduction propertics in control and SCI subjects (posterior tibial nerve)

\begin{tabular}{|c|c|c|c|c|c|c|c|c|c|c|c|c|c|c|}
\hline & & & \multicolumn{4}{|c|}{ Precooling } & \multicolumn{4}{|c|}{ Cooled } & \multicolumn{4}{|c|}{ Rewarmed } \\
\hline & & & \multicolumn{2}{|c|}{ Control } & \multicolumn{2}{|c|}{ SCI } & \multicolumn{2}{|c|}{ Control } & \multicolumn{2}{|c|}{ SCI } & \multicolumn{2}{|c|}{ Control } & \multicolumn{2}{|c|}{ SCI } \\
\hline & & & Mcan & SD & Mcan & SD & Mcan & SD & Mcan & SD & Mcan & SD & Mcan & SD \\
\hline \multicolumn{15}{|c|}{ Peripheral segment } \\
\hline \multirow[t]{2}{*}{ Distal } & $\mathrm{PF}$ & Lat (PF/N9) & 8.63 & ().64 & 8.79 & $1 .(14$ & 9.44 & 0.99 & 9.52 & 1.52 & 8.84 & 1.07 & 9.03 & 1.87 \\
\hline & Ankle-PF & $\mathrm{NCV}\left(\mathrm{ms} \quad{ }^{\prime}\right)$ & 46.76 & 4.18 & 47.15 & 6.91 & 43.32 & 4.81 & 43.88 & $7 .(13$ & 46.18 & 5.93 & 46.67 & 8.54 \\
\hline \multirow[t]{2}{*}{ Proximal } & $\mathrm{L} 1$ & Lat(L1/N22) & 22.50 & 1.12 & 23.57 & 1.46 & 23.98 & 1.48 & 24.52 & 1.89 & 22.91 & 1.38 & 23.67 & 1.27 \\
\hline & $\mathrm{PF}-\mathrm{L} 1$ & $\mathrm{NCV}\left(\mathrm{ms}{ }^{\prime}\right)$ & 44.56 & 4.188 & 39.98 & 3.70 & 43.29 & 4.17 & 39.58 & 5.2() & 44.13 & 3.73 & $4(1) .67$ & 5.39 \\
\hline $\begin{array}{l}\text { Central } \\
\text { segment }\end{array}$ & $\mathrm{Ll}-\mathrm{Cz}$ & $\mathrm{CCT}(\mathrm{ms})$ & 10.93 & 1.21 & 17.97 & 7.23 & 10.93 & 2.96 & 19.01 & 7.53 & 10.68 & 1.35 & 17.08 & 7.113 \\
\hline \multirow{8}{*}{$\begin{array}{l}\text { SEP cortical } \\
\text { potentials }\end{array}$} & $\mathrm{Cz} / \mathrm{N} 33$ & Lat (ms) & 33.44 & 1.50 & 41.48 & 7.39 & 34.91 & 2.50 & 43.33 & 7.93 & 33.59 & 2.40 & 4() .76 & 7.78 \\
\hline & & Amp (uV) & 1.89 & 0.99 & 0.78 & 0.63 & 1.70 & 1.01 & 0.98 & 0.72 & 1.83 & 1.07 & 0.71 & 0.76 \\
\hline & $\mathrm{Cz} / \mathrm{P} 38$ & Lat $(\mathrm{ms})$ & 39.16 & 1.59 & 48.30 & 7.19 & 41.20 & 2.69 & 52.18 & 9.40 & 39.78 & 2.50 & 48.44 & 7.77 \\
\hline & & Amp (uV) & 2.97 & 1.63 & 1.14 & 0.96 & 2.87 & 1.63 & 1.6() & 0.88 & 2.98 & 1.72 & 1.08 & 1.09 \\
\hline & $\mathrm{Cz} / \mathrm{N} 46$ & Lat $(\mathrm{ms})$ & 48.06 & 2.17 & 59.58 & 7.74 & 49.84 & 3.15 & 62.08 & 9.68 & 48.72 & 2.72 & 59.72 & 8.61 \\
\hline & & Amp (uV) & 3.03 & 1.74 & 0.85 & 0.50 & 2.81 & 1.51 & 1.16 & 0.72 & 2.88 & 1.54 & 0.94 & 0.81 \\
\hline & $\mathrm{Cz} / \mathrm{P} 58$ & Lat $(\mathrm{ms})$ & 59.30 & 2.77 & 70.63 & 8.52 & 62.11 & 3.47 & 72.95 & 10.12 & 60.55 & 3.08 & 69.87 & 8.76 \\
\hline & & $A m p(u V)$ & 4.22 & 2.16 & 1.25 & 0.58 & 4.26 & 2.43 & 1.53 & $(0.89$ & 4.05 & 2.39 & 1.36 & 1.11 \\
\hline
\end{tabular}

Lat $=$ latency. $\quad$ Amp $=$ amplitude. 

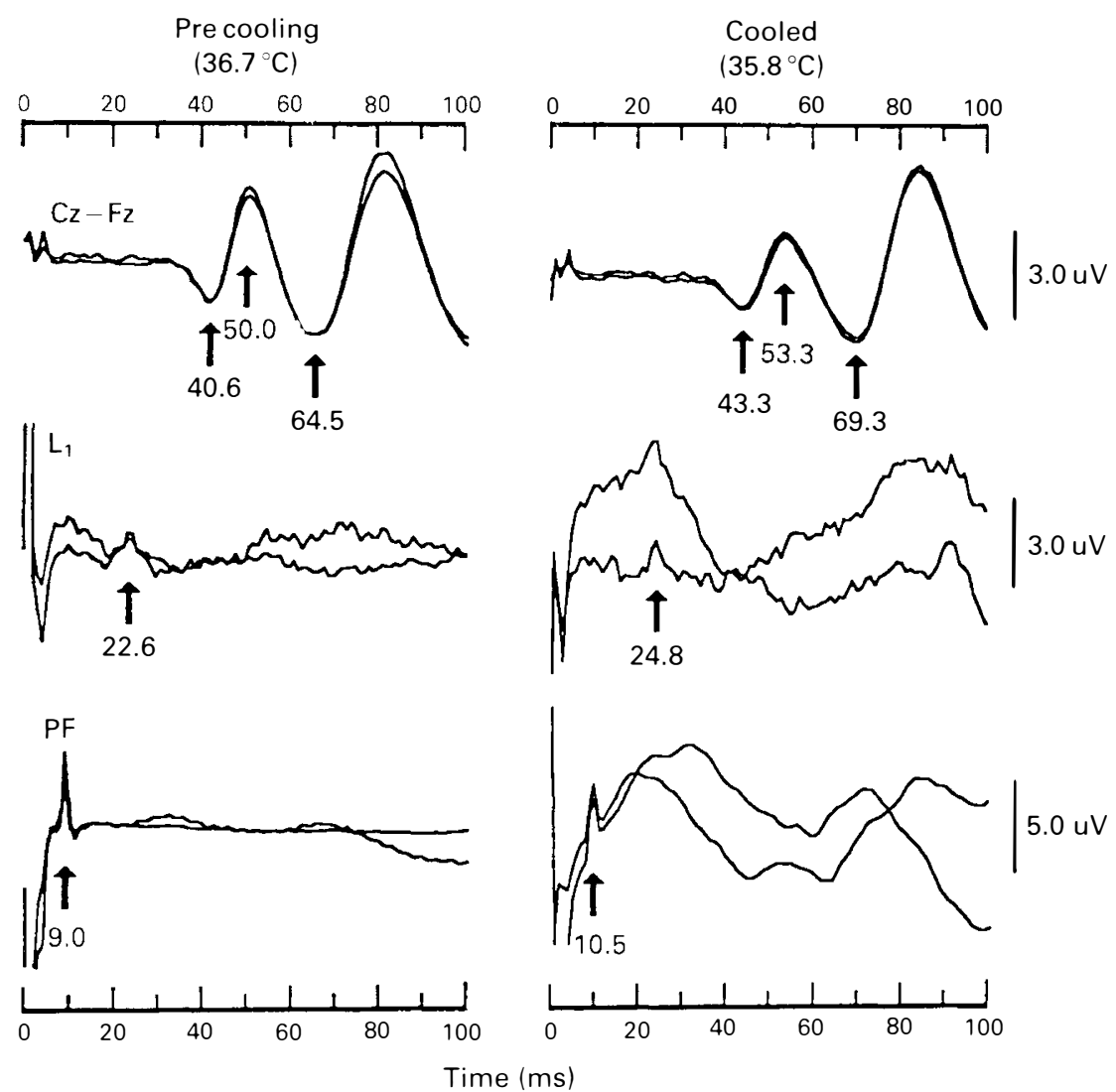

Figure 1 Effects of hypothermia on tibial nerve SEPs in a control subject. Lower traces show the tibial nerve compound potential recorded at the popliteal fossa (PF). Middle traces show spinal potentials recorded at the level of the lumbar (L1) spine. Upper traces show $\mathrm{C}_{z}-\mathrm{F}_{z}$ recording of the SEP. The latency of the $\mathrm{P}_{38}$ component was increased from $40.6 \mathrm{~ms}$ to $43.3 \mathrm{~ms}$ on cooling. The amplitude of the $\mathrm{N}_{33}-\mathrm{P}_{38}-\mathrm{N}_{46}$ complex was markedly reduced. Oral temperatures are indicated in parentheses.

$\mathrm{P}_{38}-\mathrm{N}_{46}$ component reduced form $3.03 \mu \mathrm{V}$ to $2.0 \mu \mathrm{V}$. In this subject the slowing of peripheral conduction time (medial malleolus-L1) from $22.6 \mathrm{~ms}$ to $24.8 \mathrm{~ms}$ accounted for part of the delay in onset of the cortical potential and there may have been a slight prolongation of central conduction time $\left(\mathrm{L} 1-\mathrm{C}_{\mathrm{z}}\right)$.

\section{SCI patients}

Within the SCI group, tibial nerve SEPs were only obtainable from nine patients in the precooling condition. Seven of these exhibited clearly discernible $\mathrm{N}_{33}-\mathrm{P}_{38}$ components. The group mean latency for $\mathrm{N}_{33}$ $(\bar{x}=41.48 \pm 7.4 \mathrm{~ms}) \quad$ was significantly $(p<0.05)$ longer than for the control group, and was associated with a significantly $(p<0.05)$ reduced $\mathrm{N}_{33}-\mathrm{P}_{38}$ amplitude $(\bar{x}=0.78 \pm 0.63 \mu \mathrm{V})$. The other SEP components were similarly prolonged and of low amplitude (Table III). The longer latencies were largely attributable to a prolonged $(p<0.05)$ central conduction time of $\bar{x}=$ $17.97 \pm 7.2 \mathrm{~ms}$ (compared to $\bar{x}=10.93 \pm$ $1.21 \mathrm{~ms}$ for controls).

Cooling induced longer latencies for the tibial nerve SEP $\mathrm{N}_{33}$, from the precooling value of $\bar{x}=41.5 \pm 7.4 \mathrm{~ms}$ to a cooled value of $\bar{x}=43.3 \pm 7.9 \mathrm{~ms}$. This delay was present in five of the seven patients in whom an $\mathrm{N}_{33}$ 
component was clearly discernible. At least part of the $1.85 \mathrm{~ms}$ delay was attributable to the slowed peripheral conduction since the $\mathrm{L} 1 / \mathrm{N}_{22}$ potential was consistently delayed, on average by $0.95 \mathrm{~ms}$. Central conduction time $\left(\mathrm{L} 1-\mathrm{N}_{33}\right)$ also showed a significant increase from $\bar{x}=17.97 \pm 7.23 \mathrm{~ms}$ to $\bar{x}=19.01 \pm 7.53 \mathrm{~ms} \quad(t=2.45 ; \quad d f=6$, $p<0.05)$.

In contrast to what was observed in the control group, the amplitude of $\mathrm{N}_{33}$ increased after cooling in five of the seven SCI patients with a discernible $\mathrm{N}_{33}$ component. Overall there was a $26 \%$ increase in the group mean amplitude from a precooling value of $\bar{x}=0.78 \mu \mathrm{V} \pm 0.63$ to a cooled value of $\bar{x}=0.98 \pm 0.72 \mu \mathrm{V}$. The later SEP components were also consistently increased in amplitude by $40 \%\left(\mathrm{P}_{38}-\mathrm{N}_{46}\right)$ and $37 \%\left(\mathrm{~N}_{46}-\mathrm{P}_{58}\right)$ (Table III).

Analysis of the $\mathrm{N}_{33}-\mathrm{P}_{38}$ amplitude change on a case by case basis revealed two SCI patients with amplitude changes exceeding the $50 \%$ criterion advocated for detection of clinically significant change. ${ }^{41}$ Coolinginduced increases in SEP amplitude were also observed in the two SCI patients in whom median nerve SEPs were recorded. Both exhibited cooling-induced increases in amplitude of $\mathrm{P}_{15}$ and $\mathrm{N}_{20}$, with one of the patients showing increases as large as $87 \%$ for $\mathrm{P}_{15}$ and $185 \%$ for $\mathrm{N}_{20}$. A sign test applied to the change in amplitude of the earliest discernible cortical components $\left(X^{2}=7.08\right.$; $d f=1 ; p<0.05)$ revealed a significant difference in response between the control subjects and the group of SCI patients.

All increases in tibial nerve SEP amplitude reversed when the patients were rewarmed, although they did not necessarily return to precooling values by the time of discontinuation of the studies $(\sim$ after 90 minutes of warming, with oral temperatures returned virtually to precooling values). Cooling did not result in the appearance of SEPs in those patients $(n=5)$ who did not exhibit SEPs prior to cooling.

Figure 2 illustrates the effects of cooling on tibial nerve SEPs in a male 23 year old C4 quadriparetic SCI patient (Frankel class C) with diminished lower extremity sensation to touch, temperature and pain. Cooling resulted in marked increases in the
$\mathrm{N}_{33}-\mathrm{P}_{38}$ component and the $\mathrm{P}_{38}-\mathrm{N}_{46}$ component. Later components of the waveform were similarly enhanced. The latency of the $\mathrm{N}_{33}$ component was prolonged from 35.0 to $37.3 \mathrm{~ms}$ by cooling, principally due to slowed peripheral conduction. The L1 latency increased from $23.0 \mathrm{~ms}$ to $24.3 \mathrm{~ms}$ on cooling. The noisy appearance of the L1 trace in this figure was associated with marked shivering in the patient.

Figure 3 illustrates tibial nerve SEPs obtained from two SCI patients who both exhibited marked increases in the amplitude of the cortical response, with cooling, that reversed on warming. The upper traces were from a 26 year old male $\mathrm{C} 6-7$ quadriparetic patient. Prior to cooling the tibial nerve SEP was low amplitude $\left(\mathrm{P}_{38}-\mathrm{N}_{46}=0.83 \mu \mathrm{V}\right)$ and with delayed and variable onset $\left(\mathrm{P}_{38} \sim 41.2 \mathrm{~ms}\right)$. The delay was attributable to a slowing in central conduction since the $\mathrm{L} 1$ spinal potential had a normal latency of $23.3 \mathrm{~ms}$. When cooled the $\mathrm{P}_{38}-\mathrm{N}_{46}$ amplitude increased by $53 \%$. The latency of $\mathrm{N}_{46}$ changed from 52.5 to $54.1 \mathrm{~ms}$. On warming, the SEP amplitude and latency changes were reversed. The lower traces were obtained from a 26 year old C5 quadriparetic patient who did not exhibit a clearly discernible $\mathrm{N}_{33}-\mathrm{P}_{38}$ component. Cooling induced a marked increase in amplitude $(\sim 77 \%)$ of a later component of the cortical response with negative peak at $70-75 \mathrm{~ms}$.

\section{Discussion}

The present study was undertaken to determine the effects of induced whole body hypothermia on the amplitude and latency of somatosensory evoked potentials in control subjects and SCI patients. Implicit in the rationale was that identification of patients with conduction deficits that are attenuated by cooling would indicate those patients with focal demyelination contributing to their sensory loss, who might benefit from pharmaceutical intervention with a $\mathrm{K}^{+}$ channel blocking agent. ${ }^{37}$

In control subjects whole body hypothermia yielded marked slowing of peripheral nerve conduction velocity in the tibial and 


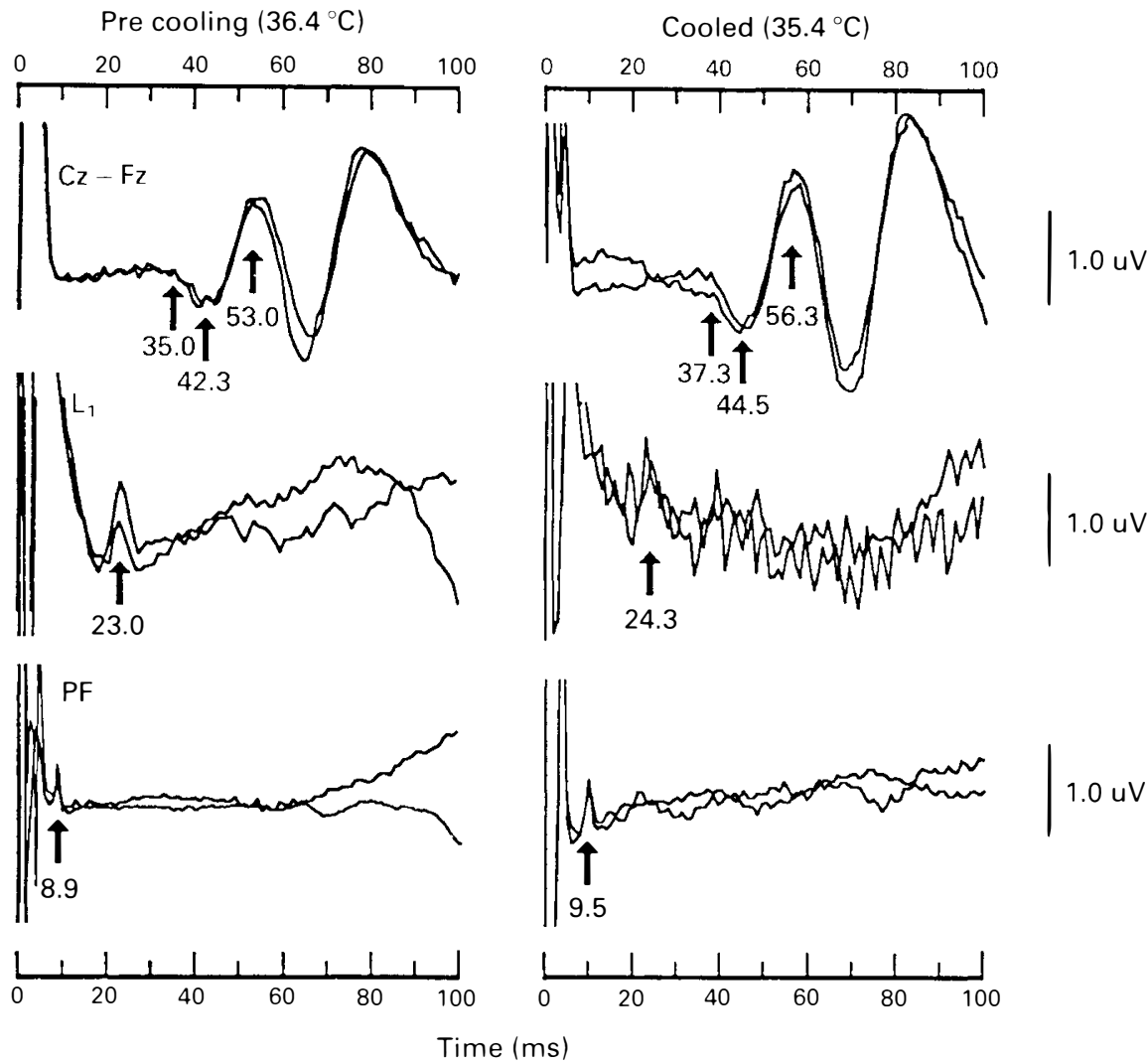

Figure 2 Effects of hypothermia on tibial nerve SEPs in a male 23 year old SCI patient with Frankel class $C 4$ quadriparesis. Lower traces show the tibial nerve compound potential $(\approx 9 \mathrm{~ms})$ at the popliteal fossa $(\mathrm{PF})$. Middle traces show spinal potentials $(\approx 23 \mathrm{~ms})$ recorded at the level of the lumbar (L1) spine. Cooling-induced shivering caused the unstable baseline in the centre traces. Upper traces show $\mathrm{C}_{2}-\mathrm{F}_{\mathrm{z}}$ recording of the cortical SEP. The latency of $\mathrm{P}_{38}$ increased from $42.3 \mathrm{~ms}$ precooling (interpolated and averaged peak) to $44.5 \mathrm{~ms}$ after cooling. Cooling induced an increase in amplitude of $\mathrm{N}_{33}-\mathrm{P}_{38}(41 \%)$ and $\mathrm{P}_{38}-\mathrm{N}_{46}(45 \%)$.

median nerves. The change in tibial nerve conduction velocity, from $46.76 \mathrm{~ms}^{-1}$ to $43.32 \mathrm{~ms}^{-1}$ was consistent with the known $\mathrm{Q}_{10}$ for $\mathrm{NCV}$ in peripheral nerves $(1.4-1.6)$ given the observed reduction $\left(2.52^{\circ} \mathrm{C}\right)$ in skin temperature. ${ }^{42-44}$ The central sensory conduction time was essentially unchanged by the whole body hypothermia, with precooling values of $\bar{x}=10.93 \pm 1.2 \mathrm{~ms}$ and postcooling values of $\bar{x}=10.93 \pm 2.9 \mathrm{~ms}$. This suggests that in the control subjects there was insufficient cooling within the cord per se (ie $<1.0^{\circ} \mathrm{C}$ ) to yield any detectable change in central conduction velocity. $\left(Q_{10}\right.$ is the ratio of highest to lowest velocity over a $10^{\circ} \mathrm{C}$ range. Hume and
Durkin ${ }^{42}$ have estimated the $\mathrm{Q}_{10}$ for fibers in the dorsal columns (1.53), medial lemniscus (1.84) and thalamocortical radiations (2.04).) The slowing of conduction in the tibial nerve was thus responsible for the delayed onset of the $\mathrm{N}_{33}$ component of the SEP (delay $=1.47 \mathrm{~ms}$ ). The later cortical SEP components were further prolonged (Table III) with additional delays introduced most probably by the effects of cooling on neural transmission. ${ }^{45}$

The present results are thus consistent with previous reports of deep hypothermia on SEPs in neurologically normal patients which have noted amplitude reduction and latency prolongation of the primary cortical 
Pre cooling

C6-7 Quadriparetic

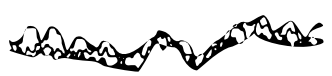

$\left(36.1^{\circ} \mathrm{C}\right)$

C5 Quadriparetic

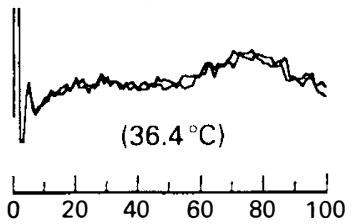

Cooled

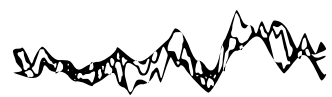

$\left(35.0^{\circ} \mathrm{C}\right)$

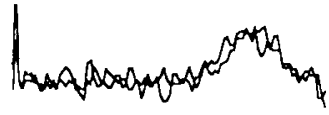

$\left(35.5^{\circ} \mathrm{C}\right)$

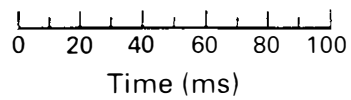

Warmed

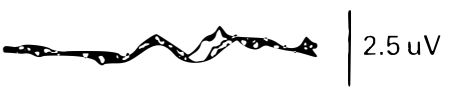

$\left(35.8^{\circ} \mathrm{C}\right)$

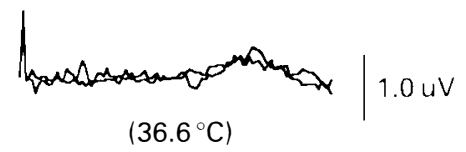

$\left(36.6^{\circ} \mathrm{C}\right)$

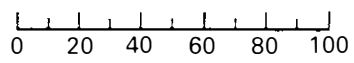

Figure 3 Effects of hypothermia on tibial nerve SEPs in two SCI patients showing marked (75\%) increases in amplitude of the cortical response that reversed on warming. The upper traces were obtained from a male C6-7 quadriparetic patient and the lower traces from a male C5 quadriparetic patient who did not exhibit a discernible $\mathrm{N}_{33}-\mathrm{P}_{3,5}$ component. In both cases there was considerable variability in the timing of the various components of the waveform, but a clear increase in amplitude of the SEP.

(and later) responses following median nerve stimulation. ${ }^{42.46 .47}$ Similar observations have also been made in animal studies of the effects of cooling on SEPs. ${ }^{+8.49}$

In the SCI patients involved in the present study, the distal segment peripheral nerve conduction velocity was reduced on cooling from $47.15 \pm 6.91 \mathrm{~ms}^{-1}$ to $43.88 \pm 7.03$ $\mathrm{ms}^{-1}$. This resulted in the latency of the spinal potential at $\mathrm{L} 1$ being delayed by $\bar{x}=1.04 \mathrm{~ms}$. The $\mathrm{N}_{33}$ component of the SEP was also delayed, from a precooling value of $41.48 \mathrm{~ms}$ to $43.33 \mathrm{~ms}$. Thus the delay in the earliest cortical component $\left(\mathrm{N}_{33}\right)$ appeared in part attributable to slowing in peripheral nerve conduction velocity but in part to a lengthening of central conduction time from 17.97 to $19.01 \mathrm{~ms}$. This implies that there was more of a cooling effect in the cord of the SCI patients than in the controls, perhaps related to their diminished thermoregulatory capability.

The most important observation in the present study was that cooling induced a different type of effect on the amplitude of SEPs in SCI patients than it did in control subjects. Nine out of eleven incomplete SCI patients (ie seven tibial and two median nerves) showed a cooling-induced increase in amplitude of the earliest recorded SEP cortical component. Prior to cooling the amplitude of the earliest component $\left(\mathrm{N}_{33}=0.78 \mu \mathrm{V} ; \mathrm{N}_{15}=1.0 \mu \mathrm{V}\right)$ was reduced in comparison to the control group and other normal values but similar to previously reported values for SCI patients. ${ }^{5(1-52}$ After cooling the amplitude increased $\left(\mathrm{N}_{33}=0.98 \mu \mathrm{V} ; \mathrm{N}_{15}=1.86 \mu \mathrm{V}\right)$. Some of the increases in amplitude were trivially small and within variability normally associated with repeated testing. However, three patients exhibited increases of amplitude $>50 \%$ with cooling. This is in contrast to the control group in which 10 of the 12 subjects exhibited reduced amplitude SEPs. One of two SCI patients who showed no appreciable change in $\mathrm{N}_{33}$ amplitude on cooling had anterior spinal artery syndrome and normal amplitude and latency SEPs. The other patient was a male T9 paraparetic with asymmetric lower limb paresis and sensory loss as a result of trauma. This patient exhibited a small reduction in SEP amplitude similar to that observed in control subjects, thereby indicating that his preserved sensory pathways were probably fully myelinated. All of the observed changes in SEP amplitude reversed on warming. The increased SEP amplitude on cooling, particularly in the three SCI 
patients with greater than $50 \%$ change from their baseline conditions, constitute evidence in support of the a priori hypothesis that whole body hypothermia would attenuate the central conduction deficits in some SCI patients.

The physiological basis for the hypothermia induced enhancement of central conduction, as manifest in increased amplitude of median and tibial nerve SEPs, most probably resides in the known extreme temperature sensitivity of conduction block in experimentally injured or demyelinated neurons. ${ }^{24}$ Davis $^{26}$ has shown that temperature reductions as small as $0.2^{\circ} \mathrm{C}$ can restore conduction in mechanically or thermally injured axons. Slight temperature variations are also known to induce marked changes in signs and symptoms of patients with MS or other demyelinating diseases. ${ }^{35.36 .53-56}$ The effect of cooling on conduction in demyelinated neurons appears to be mediated through a prolongation of the action current which increases the safety factor for conduction across the demyelinated zone. Cooling prolongs the duration of the action potential, an effect which in turn probably originates from the effect of cooling on the rate constant for $\mathrm{Na}+$ inactivation. . $^{7.23-30}$

The effectiveness of the increased safety factor in restoring conduction depends upon (a) the magnitude of the temperature dependent increase in action current and (b) the extent of demyelination. Schauf and Davis $^{29}$ modelled these properties and showed that even small reductions in temperature should restore conduction in blocked neurons with minimal degrees of demyelination. Conduction should be restored in more severely demyelinated neurons at greater reductions in temperature. Conversely, slight warming produces a marked increase in the number of neurons in which conduction would be blocked.

It seems plausible, therefore, that in the present study the induced whole body hypothermia restored conduction in some minimally demyelinated neurons that were blocked at normal body temperature. Thus, cooling slowed the conduction velocity and impaired neural transmission in spared fully myelinated neurons and in the normally myelinated segments of focally demyelinated neurons, while overcoming some of the conduction block in some partially demyelinated neurons. The slowed conduction would have been more pronounced in the peripheral nerves where the temperature reduction was greatest. The increased amplitude of SEPs, with prolongation in latency of the earliest component of the SEP, can be explained in these terms.

Of interest were observations that (a) the oral temperature continued to drop linearly for 10-15 minutes after the cooling garment was switched off and (b) the effects of cooling on SEP amplitude were oftentimes not reversed at a rate commensurate with the degree of rewarming. Similar observations have been made in studies of coolinginduced changes in clinical signs in patients with MS (R Spertell, personal communication). The tendency for oral temperature to continue to drop after the removal of the cooling agent (the so called 'after-fall' phenomenon) involves a hemodynamic response governed by the core-surface temperature gradient. ${ }^{40}$ The prolonged effect on central conduction might thus be attributable to changes in cord temperature brought about by the hemodynamic response, or to hysteresis-like behaviour of the cooling-induced changes in voltagegated ion channel kinetics.

In summary, the present results have confirmed previous reports of the effects of hypothermia in neurologically normal subjects, and more importantly have shown, for the first time, that in some SCI patients with central conduction deficits, cooling enhanced central conduction, as manifest by increased amplitude of the SEPs. These observations are consistent with the emerging view that demyelination-induced central conduction deficits constitute part of the pathophysiology of contusion/compressive lesions to the spinal cord, and these deficits may be partially and temporarily ameliorated by cooling. The results also strengthen the argument that other agents that increase the safety factor for conduction, such as 4-Aminopyridine, may enhance central conduction in some SCI patients. ${ }^{37}$ 


\section{Acknowledgements}

The authors gratefully acknowledge advice provided by Dr D Stefoski, Department of Neuro- logy, Rush University Chicago, IL regarding use of the microclimate garment. This work was funded through a grant from the American Paralysis Association.

\section{References}

1 McDonald WI (1975) Mechanisms of functional loss and recovery in spinal cord damage: In: Ciba Foundation Symposium 34 (new series). Symposium on the Outcome of Severe Damage to the Central Nervous System. Elsevier, Amsterdam: 23-33.

2 Wakefield CL, Eidelberg E (1975) Electron microscopic observations of the delayed effects of spinal cord compression. Exp Neurol 48: 637-646.

3 Yeo JD (1976) A review of experimental research in spinal cord injury. Paraplegia 14: 1-11.

4 Young W, Yen V, Blight A (1982) Extracellular calcium ionic activity in experimental spinal cord contusion. Brain Research 253: 105-113.

5 Dimitrijevic MR (1988) Residual motor functions in spinal cord injury. In: Waxman SE, editor. Adiances in Neurology 47. Functional Recovery in Neurological Disease. Raven Press. NY.

6 Blight AR (1983) Cellular morphology of chronic spinal cord injury in the cat: Analysis of myelinated axons by line-sampling. Neuroscience 10(2): 521-543.

7 Blight AR (1983) Axonal physiology of chronic spinal cord injury in the cat: Intracellular recording in vitro. Neuroscience 10: $1471-1486$.

8 Blight AR (1985) Delayed demyelination and macrophage invasion: A candidate for secondary cell damage in spinal cord injury. Cent Nerv' Syst Trauma 2: 299-314.

9 Blight AR, Young W (1989) Central axons in injured cat spinal cord recover electrophysiological function following remyelination by Schwann cells. J Neurol Sci 91: 15-34.

10 Gledhill RF, Harrison BM, McDonald WI (1973) Demyelination and remyelination after acute spinal cord compression. Exp Neurol 38: 472-487.

11 McDonald WI (1974) Remyelination in relation to clinical lesions of the central nervous system. Br Med Bull 30: 186-189.

12 Harrison BM, McDonald WI (1977) Remyelination after transient experimental compression of the spinal cord. Ann Neurol 1: 542-551.

13 Gledhill RF, McDonald WI (1977) Morphological characteristics of central demyelination and remyelination. A single fiber study. Ann Neurol 1: 552-560.

14 Bunge RP, Puckett WR. Becerra JL, Marcillo A. Quencer RM (1993) Observations on the pathology of human spinal cord injury: A review and classification of 22 new cases with details from a case of chronic cord compression with extensive focal demyelination, In: Seil FJ. editor. Neural Regeneration 59. Raven Press, NY: 75-89.

15 Chiu SY, Ritchie JM (1980) Potassium channels in nodal and internodal axonal membrane in mammalian myelinated fibres. Nature 284: 170-171.

16 Chiu SY, Ritchie JM (1981) Evidence for the presence of potassium channels in the internodal region of acutely demyelinated mammalian single nerve fibres. J Physiol (Lond) 313: 415-437.

17 Koles ZJ, Rasminsky M (1972) A computer simulation of conduction in demyelinated nerve fibres. J Physiol (Lond) 227: 351-364.

18 McDonald WI, Sears TA (1970) The effect of experimental demyelination on conduction in the central nervous system. Brain 93: 583-598.

19 Sakatani K, Ohta T, Shimo-oku M (1987) Conductivity of dorsal column fibers during experimental spinal cord compression and after decompression at various stimulus frequencies. Cent Nerv Syst Trauma 4: 161-179.

20 Sakatani K, Iizuka H, Young W (1991) Randomized double pulse stimulation for assessing stimulus frequency-dependent conduction in injured spinal and peripheral axons. EEG Clin Neurophysiol 81: $108-117$

21 Waxman SG (1988) Biophysical mechanisms of impulse conduction in demyelinated axons. In: Waxman SG, editor. Functional Recovery in Neurological Disease. Raven Press, New York: 185-214.

22 Waxman SG (1989) Demyelination in spinal cord injury. J Neurol Sci 91: 1-14.

23 Blight AR (1989) Effect of 4-Aminopyridine on axonal conduction-block in chronic spinal cord injury. Brain Res Bull 22: 47-52.

24 Davis FA, Jacobson S (1971) Altered thermal sensitivity in injured and demyelinated nerve: A possible model of temperature effects in multiple sclerosis. J Neurol Neurosurg Psychiatry 34: 551-561.

25 Brismar T (1980) Potential clamp analysis of membrane currents in rat myelinated nerve fibres. $J$ Physiol (Lond) 298: 171-184.

26 Davis FA (1970) Axonal conduction studies based on some considerations of temperature effects in multiple sclerosis. EEG Clin Neurophysiol 28: 281-286.

27 Frankenhaeuser B, Moor LE (1963) The effect of temperature on the sodium and potassium permeability 
changes in myelinated nerve fibres of Xenopus laevis. J Physiol (Lond) 169: 431-437.

28 Louis AA, Hotson JR (1986) Regional cooling of human nerve and slowed NA+ inactivation. EEG Clin Neurophysiol 63: $371-375$.

29 Schauf CL, Davis FA (1974) Impulse conduction in multiple sclerosis: a theoretical basis for modification by temperature and pharmacological agents. J Neurol Neurosurg Psychiatry 37: 152-161.

30 Rasminsky M (1973) The effects of temperature on conduction in demyelinated single nerve fibres. Arch Neurol 28: 287-292.

31 Watson CW (1959) Effect of lowering of body temperature on the symptoms and signs of multiple sclerosis. $N$ Engl J Med 261: 1253-1259.

32 VanDieman HAM, VanDongen MMMM, Dammers JWHH, Polman CH (1992) Increased visual impairment after exercise (Uhthoff's phenomenon) in multiple sclerosis: Therapeutic possibilities. Eur Neurol 32: 231-234.

33 Boynton BL, Garramone PM, Buca J (1985) Observations on the effects of cool baths for patients with multiple sclerosis. Phys Ther Rev 39: 297-299.

34 Symington GR, MacKay IR, Currie TT (1977) Improvement in multiple sclerosis during prolonged induced hypothermia. Neurology 27: 302-303.

35 Nelson DA. McDowell E (1959) The effects of induced hyperthermia on patients with multiple sclerosis. $J$ Neurol Neurosurg Psychiatry 11: 113-116.

36 Namerow NS (1968) Circadian temperature rhythm and vision in multiple sclerosis. Neurology 18: 417-422.

37 Hayes KC, Blight AR, Potter PJ, Allatt RD, Hsieh JTC, Wolfe DL et al (1993) Preclinical trial of 4-Aminopyridine in patients with chronic spinal cord injury. Paraplegia 31: 216-224.

38 Cooper KE. Cranston WI. Snell ES (1964) Temperature in the external auditory meatus as an index of central temperature changes. J Appl Physiol 19: 1032-1035.

39 Chiappa KH, editor (1990) Evoked Potentials in Clinical Medicine. Raven Press, New York.

40 Blair E (1964) Clinical Hypothermia. McGraw-Hill, New York.

41 DeLisa J. Mackenzie K. Baran E (1987) Manual of Nerve Conduction Velocity and Somatosensory Evoked Potentials. 2nd ed. Raven Press, New York: 190-200.

42 Hume AL, Durkin MA (1986) Central and spinal somatosensory conduction times during hypothermic cardiopulmonary bypass and some observations on the effects of fentanyl and isoflurane anesthesia. EEG Clin Neurophysiol 65: 46-58.

43 De Jesus PV. Hausmanowa-Petrusewicz I, Barchi RL (1973) The effect of cold on nerve conduction of human slow and fast nerve fibers. Neurology 23: 1182-1189.

tt de Jong RH, Hershey WN, Wagman IH (1966) Nerve conduction velocity during hypothermia in man. Anesthesiology 27: 805-810.

45 Benita M. Conde H (1972) Effects of local cooling upon conduction and synaptic transmission. Brain Res 36: $133-151$.

46 Stejskal L. Travnicek V, Sourek K. Kredba J (1980) Somatosensory evoked potentials in deep hypothermia. Appl Neurophysiol 43: 1-7.

47 Markand ON. Warren CH. Moorthy SS, Stoelting RK, King RD (1984) Monitoring of multimodality evoked potentials during open heart surgery under hypothermia. EEG Clin Neurophysiol 59: 432-440.

48 Budnick B. McKeown KL. Wiederholt WC (1981) Hypothermia-induced changes in rat short latency somatosensory evoked potentials. EEG Clin Neurophysiol 51: 19-31.

49 Oro J. Haghighi S (1992) Effects of altering core body temperature on somatosensory and motor evoked potentials in rats. Spine 17: 498-503.

50 Perot PL (1973) The clinical use of somatosensory evoked potentials in spinal cord injury. Clin Neurosurg 20: $367-381$.

51 Riffel B. Stohr M, Korner S (1984) Spinal and cortical evoked potentials following stimulation of the posterior tibial nerve in the diagnosis and localisation of spinal cord diseases. EEG Clin Neurophysiol 58: $400-407$.

52 Young W (1982) Correlation of somatosensory evoked potentials and neurological findings in spinal cord injury In: Tator CD, editor. Early Management of Acute Spinal Cord Injury. Raven Press, New York.

53 Simons DJ (1937) Note on effect of heat and of cold upon certain symptoms of multiple sclerosis. Bull Neurol Inst 6: 385-386.

54 Guthrie TC (1951) Visual and motor changes in patients with multiple sclerosis: A result of induced changes in environmental temperature. Arch Neurol Psychiatry 65: 437-451.

55 Bajada S, Mastaglia FL, Black JL. Collins DWK (1980) Effects of induced hyperthermia on visual evoked potentials and saccade parameters in normal subjects and multiple sclerosis patients. J Neurol Neurosurg Psychiatry 43: 849-852.

56 Matthews WB, Read DJ, Pountney E (1979) Effect of raising body temperature on visual and somatosensory evoked potentials in patients with multiple sclerosis. J Neurol Neurosurg Psychiatry 42: 250-255. 